\title{
NITROGENASE: A \\ Nucleotide-Dependent Molecular Switch
}

\author{
James B. Howard \\ Department of Biochemistry, University of Minnesota School of Medicine, \\ Minneapolis, Minnesota 55455 \\ Douglas C. Rees \\ Division of Chemistry and Chemical Engineering $147-75 \mathrm{CH}$, California Institute \\ of Technology, Pasadena, California 91125
}

KEY WORDS: nitrogen fixation, nucleotide-binding proteins, ADP/ATP, enzyme mechanism, metal clusters

\section{CONTENTS}

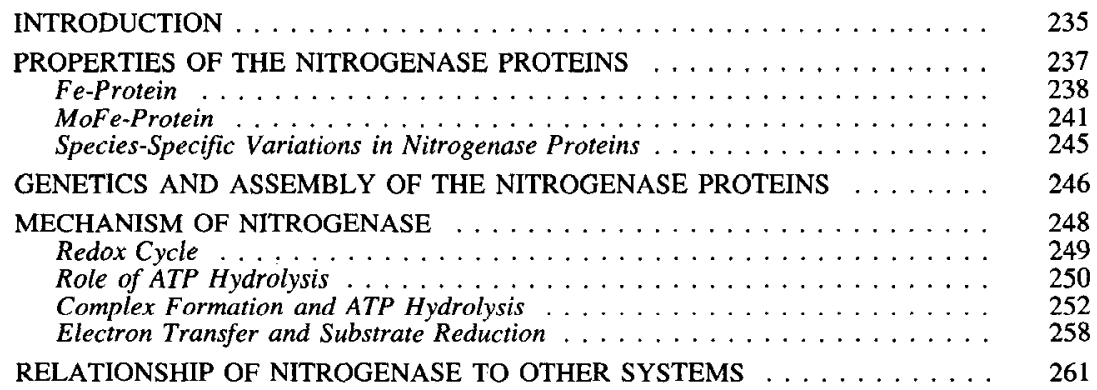

\section{INTRODUCTION}

In the simplest terms, the biological nitrogen cycle is the reduction of atmospheric dinitrogen $\left(\mathrm{N}_{2}\right)$ to ammonia with the subsequent reoxidation of ammonia to dinitrogen (1). At the reduction level of ammonia, nitrogen is incorporated into precursors for biological macromolecules such as proteins 
and nucleic acids. Reoxidation of ammonia to dinitrogen ("denitrification") by a variety of microbes (by way of nitrite and other oxidation levels of nitrogen) leads to the depletion of the "fixed," biologically usable, nitrogen pool. Besides the relatively small contribution from commercial ammonical fertilizer production, replenishing of the nitrogen pool falls mainly to a limited number of physiologically diverse microbes (e.g. eubacteria and archaebacteria; free-living and symbiotic; aerobic and anaerobic) that contain the nitrogenase enzyme system.

During the past 25 years, steady progress has been made in elucidating the essential elements of the nitrogenase reaction (reviewed in 2-8a), which are summarized in Figure 1. Ammonia synthesis requires eight electrons: six for the reduction of dinitrogen and two for the coupled, obligatory synthesis of $\mathrm{H}_{2}$ (9). These reactions are catalyzed by the terminal component in the complex, the MoFe-protein, ${ }^{1}$ so-designated because it contains iron and molybdenum atoms. Electrons are transferred to the MoFe-protein from the Fe-protein in a process coupled to the hydrolysis of two ATP per electron. Because a minimum of 16 ATP are hydrolyzed for the reduction of one molecule of dinitrogen, the organisms carrying out nitrogen fixation have a vigorous energy metabolism. The Fe-protein is an integral component of the nitrogenase reaction in that other, low-redox-potential electron donors do not support dinitrogen reduction, undoubtedly due to the requirement for coupled ATP hydrolysis. In contrast, a variety of electron donors (ferredoxins and flavodoxins) provide a connection between cellular metabolism and the reduction of the Fe-protein.

In the past, nitrogenase and nitrogen fixation have been of interest primarily to bioinorganic chemists and spectroscopists, and to those working in microbial physiology related to agriculture. However, the similarity of the ATP-dependent electron transfer in nitrogenase to many other nucleotide-dependent energy-transducing systems in higher organisms should make this enzyme of general interest to biochemists. The recent solution of three-dimensional structures for both the nitrogenase proteins (13-20) em-

\footnotetext{
${ }^{1}$ The nomenclature for the nitrogen fixation enzyme is rich and varied. The molybdenum-iron protein is frequently referred to as $\mathrm{MoFe}$-protein, component 1 , or dinitrogenase, while the iron protein is referred to as Fe-protein, component 2, or dinitrogenase reductase. A useful shorthand nomenclature for a component from a specific organism is to abbreviate the species followed by the number of the component, e.g. the MoFe-protein from Azotobacter vinelandii is Avl and the Fe-protein from Clostridium pasteurianum is $\mathrm{Cp} 2$. We use the shorthand when discussing specific results, and the $\mathrm{MoFe}$-protein and $\mathrm{Fe}$-protein designations when discussing generic conclusions. Amino acid residue numbering for Fe-protein is based upon the protein sequence of Av2 (10), which is one residue shorter than the gene sequence (11). The numberings for MoFe-protein subunits are based upon the gene sequences for Avl subunits (11), which are one residue longer than for the isolated protein subunits (12). In both cases, the protein apparently is processed by removal of the initiation Met.
} 


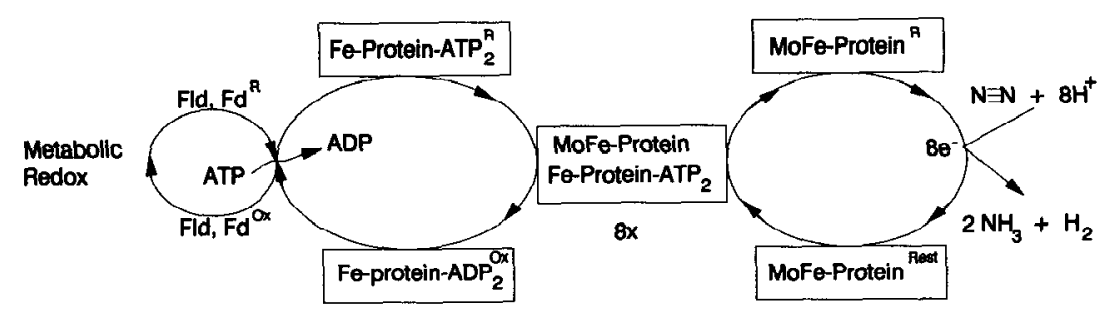

Figure 1 The nitrogenase reaction. The electron transfer proteins ferredoxin $(\mathrm{Fd})$ and flavodoxin (Fld) serve to couple the nitrogenase reaction to metabolically generated reducing equivalents.

phasizes not only the functional relatedness, but also the structural relatedness of nitrogenase to such diverse systems as ras $\mathrm{p} 21(21,22)$, membrane-bound transporters $(23,24)$, muscle contraction $(25)$, the recA protein involved in DNA recombination (26), and elongation factors in protein biosynthesis (27, 28). This review aims to summarize for the general biochemist the status of nitrogenase structure-function studies and to discuss the relevance of nitrogenase chemistry to other systems. For those wanting more detailed analysis of specific questions relating to nitrogenase, there are reports from several recent symposia $(29,30)$.

\section{PROPERTIES OF THE NITROGENASE PROTEINS}

The nitrogenase Fe-protein and MoFe-protein have been sequenced and/or characterized from a variety of nitrogen-fixing organisms. Generally speaking, the structural and functional properties of these proteins are highly conserved among different organisms. For many combinations of Fe-protein and $\mathrm{MoFe}$-protein from different species, substantial activity is obtained from these heterocomplexes; yet for others, little or no activity is observed $(31,32)$. Consequently, while we emphasize "consensus" features of these proteins, important species-specific variations exist, and are discussed when relevant.

Undoubtedly, no feature more dominates the experimental study of these proteins than their extreme oxygen lability. All manipulations of the proteins must be performed with an atmosphere of $<1 \mathrm{ppm}$ oxygen. Because of the destructive effects of even traces of oxygen, it is often difficult to separate legitimate results from artifacts generated by the experimental conditions. For nitrogenase, probably more so than for any other enzyme, the consistency of results between laboratories must be demonstrated before an "observation" should be considered a "fact." 


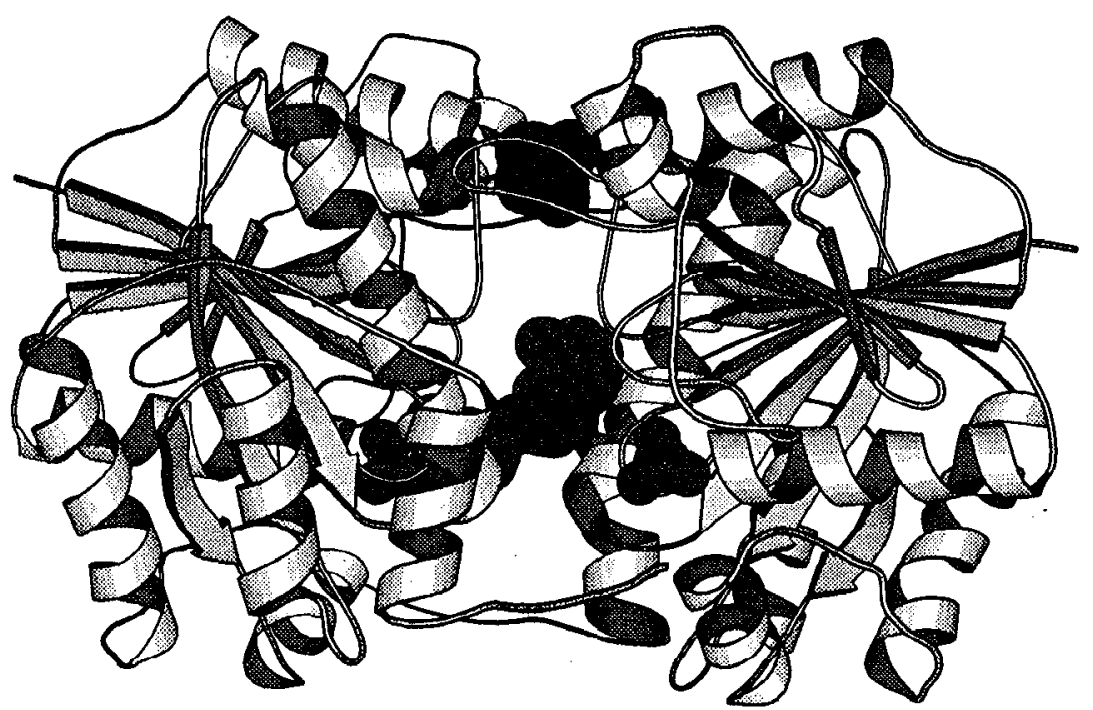

Figure 2 Ribbons diagram of the polypeptide fold of the Fe-protein dimer, with space-filling models for the $4 \mathrm{Fe}: 4 \mathrm{~S}$ cluster and ADP. Prepared with the program MOLSCRIPT (36a) and reproduced with permission from (8a).

\section{Fe-Protein}

The Fe-protein is a $\sim 60,000$-dalton dimer of identical subunits bridged by a single $4 \mathrm{Fe}: 4 \mathrm{~S}$ cluster. The three-dimensional crystal structure of Fe-protein (13) confirmed the hypothesis $(33,34)$ that the cluster is symmetrically coordinated by Cys 97 and Cys 132 from each subunit. Significantly, the subunits have the $\alpha$-helical/ $\beta$-sheet type of architecture commonly associated with a major class of nucleotide-binding proteins (35) that includes adenylate kinase (36) and the ras p21 oncogene protein $(21,22)$. The large, single domain encompassing the entire Fe-protein subunit consists of an eightstranded $\beta$-sheet flanked by nine $\alpha$-helixes (Figure 2). The two subunits are related by a molecular two-fold rotation axis that passes through the 4Fe:4S cluster, which is located at one end of the dimer, and the subunitsubunit interface. Besides the cluster serving to crosslink subunits, there are numerous hydrophobic and salt interactions in the interface beneath the cluster that help to stabilize the dimer structure. Indeed, these interactions are sufficiently strong that the cluster can be removed and the dimer structure is still maintained (34).

One of the two principal functional features of the Fe-protein is the binding of the nucleotides, MgATP and MgADP. Two nucleotide-binding 


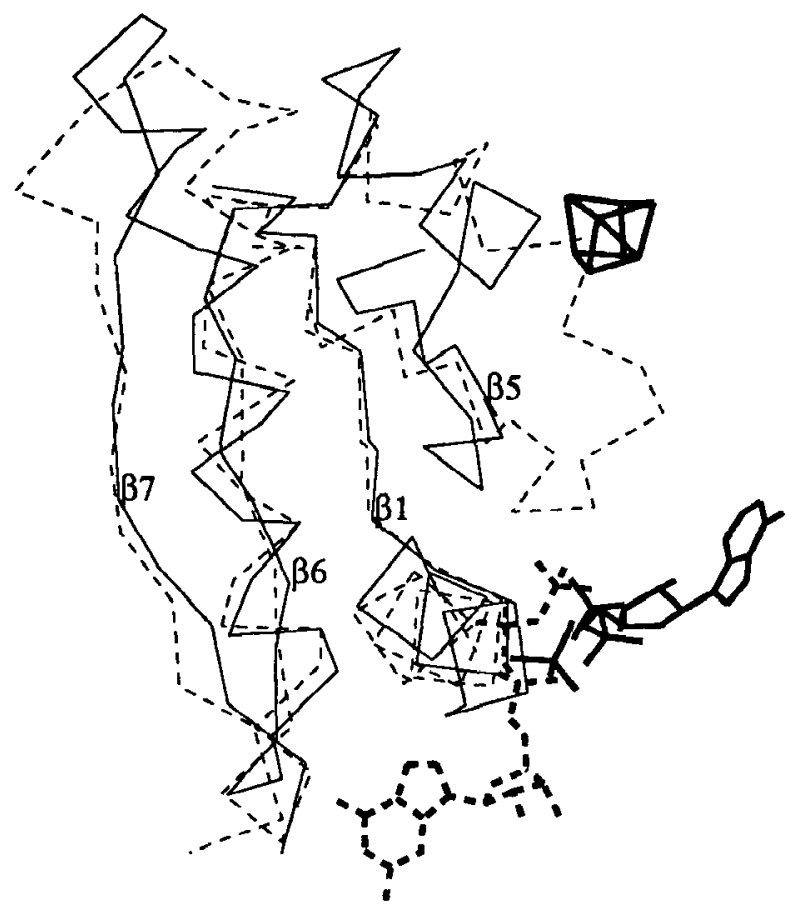

Figure 3 Two potential nucleotide-binding modes in Fe-protein based upon the observed ADP-binding mode in the Av2 crystal structure (13; solid lines) and the GTP-binding mode in ras $\mathrm{p} 21$ ( 21 ; dashed lines). The numbers of the $\beta$ strands in Av2 are indicated. Reproduced with permission from (13).

sites per dimer have been reported with dissociation constants of $\sim 100 \mu \mathrm{M}$, although there is considerable variation in the measured values (37), due in part to the difficulty of determining equilibrium values with oxygen-sensitive proteins. Residues 9-16 near the amino terminus of Fe-protein exhibit the amino acid sequence motif, GXXXXGKS [the Walker motif A (38)], that is characteristic of a major class of nucleotide-binding sites (35). This sequence adopts a $\beta$-strand-loop- $\alpha$-helix conformation that interacts with the $\beta, \gamma$-phosphate groups and the $\mathrm{Mg}$ of bound nucleotides. Mutations in Fe-protein leading to substitutions at Lys 15 and to the three hydroxy amino acids at residues 16-18 are consistent with this sequence being part of the phosphate-binding site in Av2 $(39,40)$. In addition, the second Walker motif, DxxG, that in combination with motif A completes the Mg-phosphate protein interactions, is also found in Av2 at residues 125-128. Substitution 
of glutamic acid for Asp125 confirmed the role of this residue as a ligand to $\mathrm{Mg}(41)$.

Although a ras-type nucleotide phosphate-binding site is clearly present in Fe-protein, it is less evident how the nucleotide would be oriented with respect to this site. The Walker motif $\mathrm{A}$ is located near the molecular two-fold axis of Fe-protein, and the nucleotide-binding sites project into the subunit-subunit interface. In the Av2 crystal structure, one molecule of ADP was observed to be positioned across the subunit-subunit interface, perpendicular to the two-fold axis (Figure 3). With this orientation, the purine ring is bound to one subunit and the phosphates to the other. An alternative and more speculative binding mode can be modeled by analogy to the ras protein. In this mode, the nucleotide would lie along the two-fold axis with the purine ring and phosphate groups bound by the same subunit (see Figure 3 ). There is mutagenesis evidence that may support this orientation of nucleotide binding. If invariant residue Arg213 (comparable to Lys117 in the ras structure, which is part of the purine ring-binding domain) is substituted by cysteine, the Fe-protein is inactive (42). Because $\operatorname{Arg} 213$ is located on the surface of the protein, at the extreme edge of the intersubunit cleft, substitution here would seem to be innocuous, unless it were part of a specific interaction, such as the extended nucleotide site. As described in more detail below, it is conceivable that both modes of nucleotide binding may be functionally relevant.

The second functional site in Fe-protein is the 4Fe:4S cluster, which undergoes a one-electron redox cycle between the $2 \mathrm{Fe}^{2+} 2 \mathrm{Fe}^{3+}$ state and the $3 \mathrm{Fe}^{2+} \mathrm{Fe}^{3+}$ state. Both cluster ligands are located near the amino-terminal end of $\alpha$-helices that are directed towards the cluster. Peptide bonds within these helices form NH-S hydrogen bonds to the cluster that may provide stabilizing electrostatic interactions to this anionic center (43). In contrast to the $4 \mathrm{Fe}: 4 \mathrm{~S}$ clusters observed in ferredoxin-type proteins, a striking feature of the $\mathrm{Fe}$-protein is the exposure of the $4 \mathrm{Fe}: 4 \mathrm{~S}$ cluster to solvent, a property anticipated by spectroscopic studies (44). Other than the cysteinyl ligands, there is little contact between the $4 \mathrm{Fe}: 4 \mathrm{~S}$ cluster and other amino acid side chains. Consequently, the emerging picture of the Fe-protein cluster is that of an exposed, loosely packed redox center that may function as a pivot or hinge to accommodate conformational rearrangements between subunits during the course of the nitrogenase reaction mechanism.

Although Fe-protein has a number of spectroscopic signatures typical of $4 \mathrm{Fe}: 4 \mathrm{~S}$ clusters, more important to understanding the functional properties of the protein is the response of the cluster to nucleotide binding. Some of these responses indicate that the Fe-protein is intimately involved in the coupling of ATP hydrolysis to electron transfer. For example, the electron paramagnetic resonance (EPR) spectrum becomes more axial (45), and there 
is a $60-100-\mathrm{mV}$ decrease in the redox potential when $\mathrm{AXP}^{2}$ is bound to Fe-protein (46). A dramatic effect of nucleotide binding is evidenced by the change in accessibility of the cluster to chelators (47-49). Specifically, the cluster irons can be removed by chelators only in the presence of MgATP; MgADP inhibits chelation, whereas no chelation occurs in the absence of nucleotide. Given that the cluster is already exposed to solvent, it is surprising that chelation is dependent on the presence of MgATP. Furthermore, the chelation process is dependent upon the oxidation state of the cluster (50). The crystal structure clearly shows that the binding site for the terminal nucleotide phosphates (where hydrolysis occurs) is located $\sim 20 \AA$ from the cluster, so that the nucleotide does not interact directly with the cluster. Rather, the location of the cluster and nucleotide-binding sites at the interface between the subunits suggests there is an allosteric coupling mechanism that connects these two functional sites. Different conformational states of the Fe-protein might exist that differ in details of the intersubunit interactions, e.g. changes in number or location of salt bonds. The equilibrium between these conformations must be sensitive to nucleotide binding, oxidation state of the cluster, and complex formation with the MoFe-protein. Hence, ligand-binding and/or redox reactions would shift the equilibrium position between states, thereby coupling spatially distinct processes. As described below, the details of the coupling process are one of the major, unanswered problems in the nitrogenase mechanism.

\section{MoFe-Protein}

The MoFe-protein is an $\alpha_{2} \beta_{2}$ tetramer with a total molecular weight of $\sim 240,000$. For some time, it has been recognized from the spectroscopic properties of the protein that there are two groups of metal centers: the diamagnetic, EPR-silent P-cluster pairs (or P-cluster or P-center), and the unusual $S=3 / 2$ paramagnetic FeMo-cofactor (or M-center or "cofactor"). Although there has been much speculation as to the arrangement and structure of the $2 \mathrm{Mo}, 30 \mathrm{Fe}$, and $\sim 34$ inorganic $S$ that form these clusters, the recent three-dimensional structures of the protein $(14-20)$ revealed how truly unique they are. Each of the two FeMo-cofactor units contains $1 \mathrm{Mo}: 7 \mathrm{Fe}: 9$ $\mathrm{S}$ and one homocitrate molecule, and almost certainly provides the site of substrate binding and reduction. The FeMo-cofactor may be considered to be formed from $4 \mathrm{Fe}: 3 \mathrm{~S}$ and Mo:3Fe:3S partial cubanes that are bridged by three nonprotein ligands, most probably sulfides (Figure 4). The cofactor is buried $\sim 10 \AA$ beneath the protein surface, in an environment primarily provided by the $\alpha$ subunit. Only two protein ligands, Cys $\alpha 275$ and His $\alpha 442$, coordinate the cofactor to the protein, resulting in the unusual situation

2The notation AXP designates either ADP or ATP. 


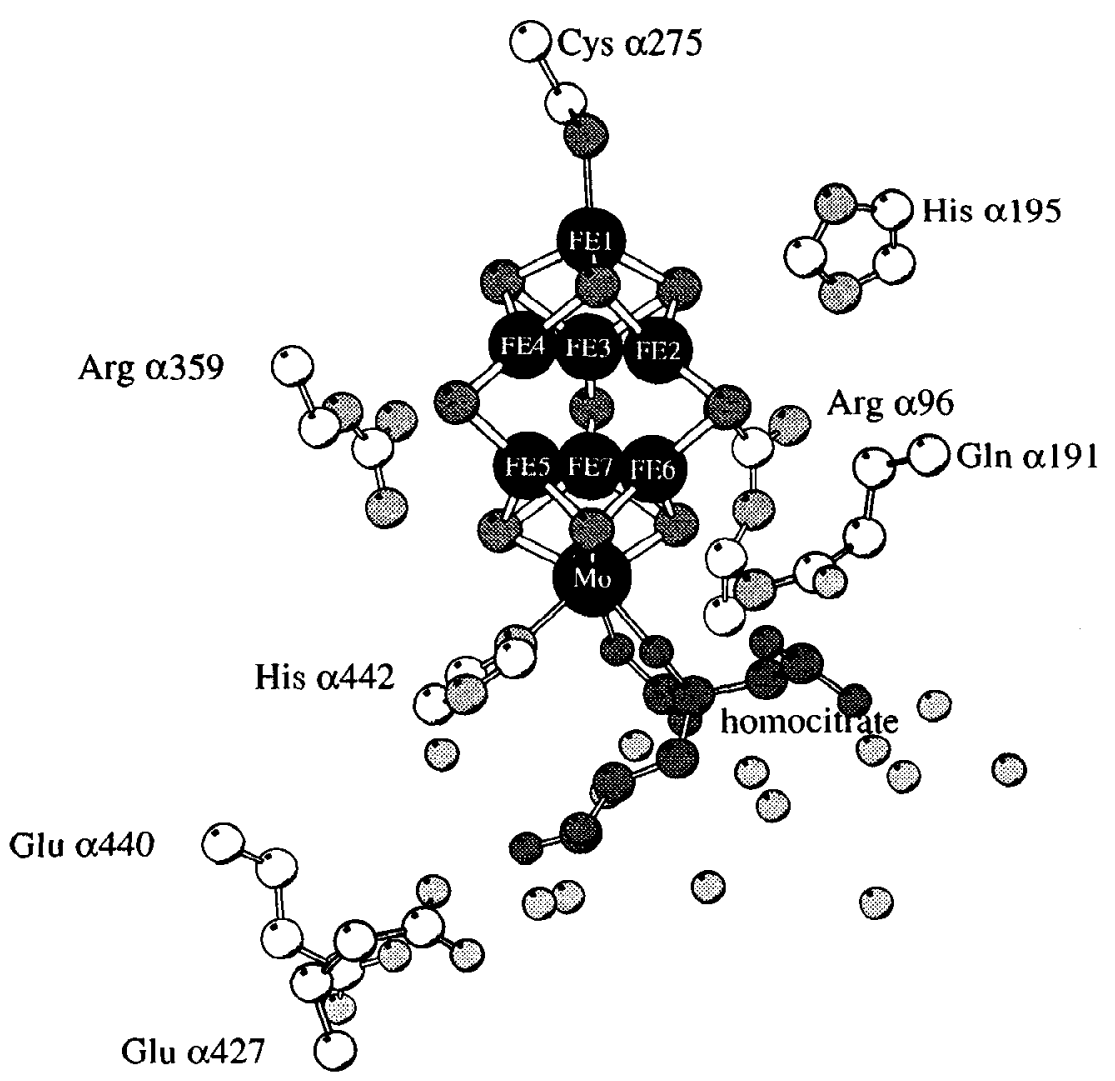

Figure 4 Structure of the FeMo-cofactor with surrounding protein and water molecules indicated. Prepared with the program MOLSCRIPT (36a), and reproduced with permission from (8a).

in which the six $\mathrm{Fe}$ atoms bridged by nonprotein ligands are three-coordinate. It is tempting to consider these unsaturated sites as suitable for binding of ligands, including substrates. The octahedral coordination sphere of the Mo is completed by bidentate binding of homocitrate. Hydrogen bonds to sulfurs in the cluster are provided by the side chains of residues Arg $\alpha 96$, His $\alpha 195$, Arg $\alpha 359$, and the NH groups of residues $\alpha 356$ and $\alpha 358$. These hydrogen bonds may provide a mechanism for funneling protons to substrate bound to the FeMo-cofactor. The homocitrate is hydrogen bonded to the side chain of $\mathrm{Gln} \alpha 191$, and is also surrounded by a pool of buried waters, which could conceivably function as a proton source for substrate reduction.

The remaining $\mathrm{Fe}$ and $\mathrm{S}$ are organized into P-cluster pairs, which are 


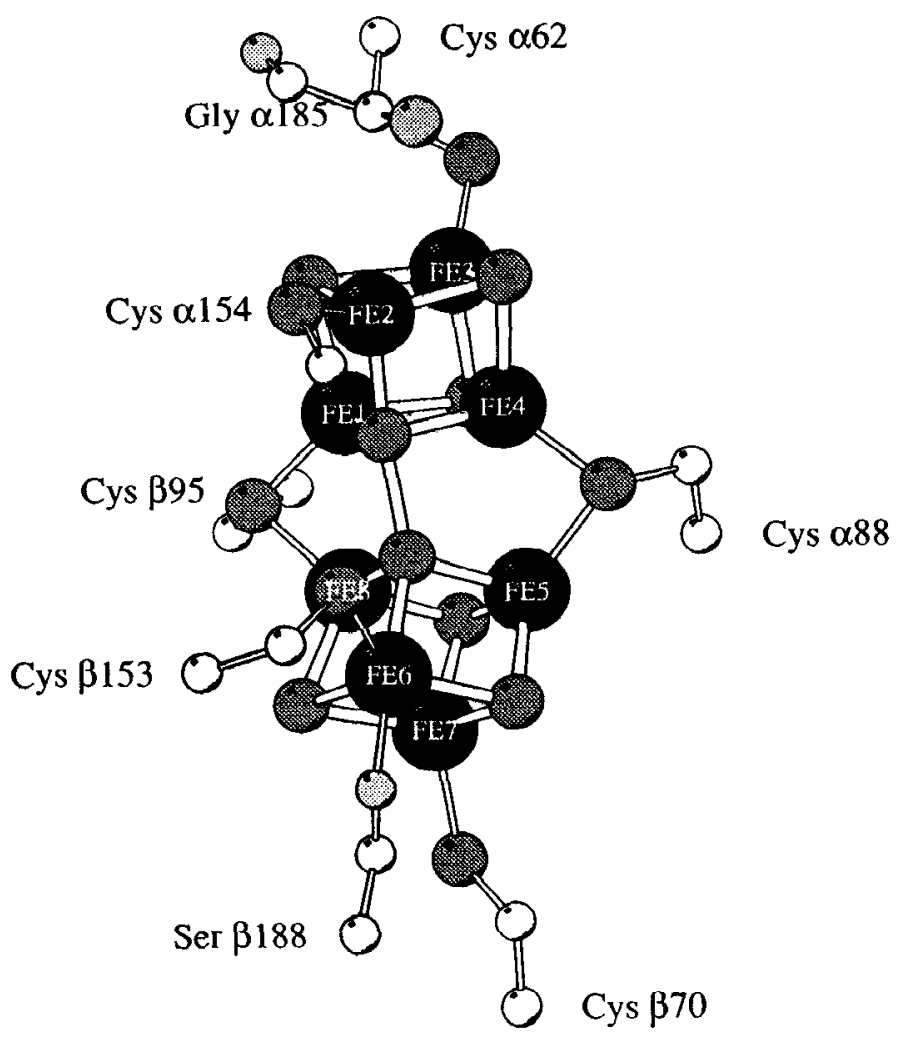

Figure 5 Structure of the P-cluster pair and surrounding protein. Prepared with the program MOLSCRIPT (36a), and reproduced with permission from (8a).

present in two copies per MoFe-protein tetramer. Each P-cluster pair contains two bridged $4 \mathrm{Fe}: 4 \mathrm{~S}$ clusters, i.e. the P-cluster pair can be considered as a $8 \mathrm{Fe}: 8 \mathrm{~S}$ cluster. What makes the $\mathrm{P}$-cluster pair an unusual inorganic structure is that the two $4 \mathrm{Fe}: 4 \mathrm{~S}$ clusters are bridged by the thiol side chains of Cys $\alpha 88$ and $\beta 95$, and a disulfide bond between two cluster inorganic sulfurs (Figure 5). Although this disulfide bridge is clear in the Av1 structure (17), Bolin's current analysis of the Cp1 structure suggests that perhaps only one sulfur is present in his structure (20). This disulfide bond is located on the side of the P-cluster pair closest to the surface of the protein. Singly coordinating cysteinyl thiols (from residues $\alpha 62, \alpha 154, \beta 70$, and $\beta 153$ ) ligate the remaining four irons, such that nonbridging cysteines coordinated to a specific $4 \mathrm{Fe}: 4 \mathrm{~S}$ cluster are from the same subunit. In addition to the 


\section{HOWARD \& REES}

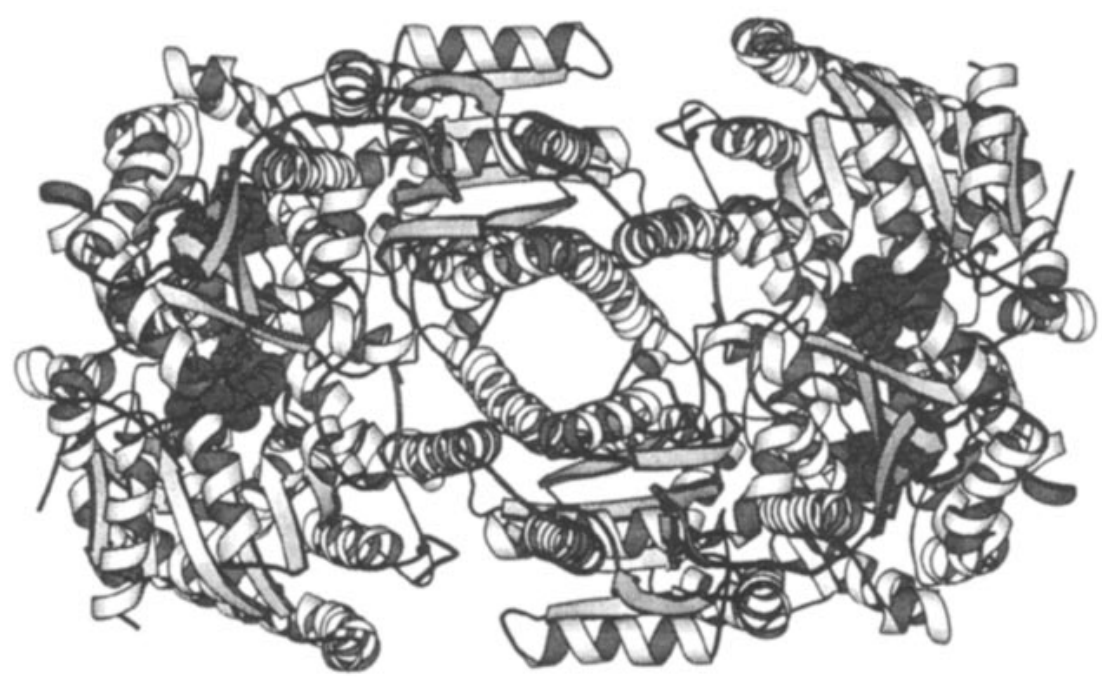

Figure 6 Ribbons diagram of the polypeptide fold of the MoFe-protein tetramer, with space-filling models for the P-cluster pair and the FeMo-cofactor. The view is along the tetramer two-fold axis. Prepared with the program MOLSCRIPT (36a) and reproduced with permission from (8a).

cysteinyl ligands, Ser $\beta 188$ appears to coordinate the same iron as Cys $\beta 153$, although in Bolin's analysis of Cp1, this side chain does not appear to serve as an iron ligand, but rather donates a hydrogen bond to a cluster sulfur (20). The presence of the disulfide bridge in the P-cluster pair implies that this center may be able to serve as a two-electron redox group. Since the Fe-protein is generally considered to be a one-electron donor with the P-cluster pair as the immediate acceptor, the P-cluster pair may exhibit both one- and two-electron redox chemistry, analogous to quinones and flavins in other biological systems. Spectroscopic studies indicate that the P-cluster pair is highly reduced, with all eight $\mathrm{Fe}$ atoms most likely in the ferrous form (51). Although the all ferrous oxidation state is unprecedented in known biological four-iron clusters, the P-cluster pair cannot be directly compared to these other clusters. Two isolated $4 \mathrm{Fe}: 4 \mathrm{~S}$ clusters with all $\mathrm{Fe}$ in the ferrous state would have a combined net charge of -8 (including the eight thiol ligands), whereas the P-cluster pair, with two bridging ligands and a disulfide, would have a net charge of only -4 . That is, the effective cluster charge per iron atom is similar to an oxidized ferredoxin cluster, not to a "super-reduced" cluster. 
Although there is minimal amino acid sequence homology between subunits, the $\alpha$ and $\beta$ subunits of Av1 exhibit similar polypeptide folds, which consist of three domains of the $\alpha$-helical/ $\beta$-sheet type with some extra helices (Figure 6). At the interface between the three domains is a wide, shallow cleft; in the $\alpha$ subunit, the FeMo-cofactor occupies the bottom of this cleft. The P-cluster pair is buried at the interface between a pair of $\alpha$ - and $\beta$-subunits with a pseudo two-fold rotation axis passing between the two 4Fe:4S halves of the P-cluster pair and relating the two subunits. Coordination of metal centers by ligands at the interface between homologous or identical subunits has been previously described for Fe-protein and bacterial photosynthetic reaction centers $(52,53)$, and may be a common feature of multisubunit metalloproteins. It should be noted that in some places, the symmetry away from the cluster interface is more apparent than real. For example, some of the symmetry-related secondary elements on the protein surface are, in fact, from different scgments of the primary sequence in the individual subunits.

The extensive interaction between $\alpha$ and $\beta$ subunits in an $\alpha \beta$ dimer suggests they form a fundamental functional unit. Intriguingly, there is an open channel of $\sim 8 \AA$ diameter between the two pairs of $\alpha \beta$ dimers with the tetramer two-fold axis extending through the center. The tetramer interface is dominated by interactions between helices from the two $\beta$ subunits, along with a cation-binding site, presumably calcium, that is coordinated by residues from both $\beta$ subunits.

\section{Species-Specific Variations in Nitrogenase Proteins}

A notable exception to heterocomplexes (mixes of Fe-protein and MoFeprotein from different species) having enzymatic activity are both the nitrogenase components from $C$. pasteurianum (Cp1 and $\mathrm{Cp} 2)(31,32)$. Structural differences between the nitrogenase proteins from $A$. vinelandii and $C$. pasteurianum have been identified that could be the source of the inability of $C$. pasteurianum proteins to complement other nitrogenase proteins. $\mathrm{Cp} 2$ differs from Av2 in the length of the carboxy-terminal residues ( $\mathrm{Cp} 2$ is 13 residues shorter than Av2) and in the region around residue 65, which exhibits significant sequence variability in different Fe-proteins, including a two-residue deletion in $\mathrm{Cp} 2$ relative to Av2. The carboxy-terminal residues of Av2 form intersubunit contacts that would not be possible in $\mathrm{Cp} 2$, due to the shorter length of this protein. Incorporation of the $\mathrm{Cp} 2$ carboxy-terminal residues into the Av2 sequence results in $\sim 50 \%$ reduction in Av2 activity (54), indicating that while these residues are not essential for $\mathrm{Fe}$-protein function in the nitrogenase mechanism, they do contribute to the overall kinetics, perhaps by influencing the relative stabilities of different Fe-protein conformations. The region around residue 65 of Av2 projects 
from the "top" surface of the protein that has been implicated in the binding of Fe-protein to MoFe-protein. Hence, sequence alterations in this region may perturb the structure or stability of the Fe-protein-MoFe-protein complex.

Cp1 differs from Av1 by a $\sim 50$-residue insertion in the $\alpha$ subunit and a $\sim 50$-residue deletion in the $\beta$ subunit. In Av1, the amino-terminal $\sim 50$ residues (that are deleted in $\mathrm{Cpl}$ ) extend from the $\beta$ subunit, and interact with both an $\alpha$ subunit and the other $\beta$ subunit. Hence, it is possible that these amino-terminal residues of the $\beta$ subunit function in stabilization of the quaternary structure of Av1. Interestingly, these amino-terminal residues are also missing from the alternative vanadium-iron protein $(55,56$; also, see below). The insertion in the $\alpha$ subunit of $\mathrm{Cp} 1$ forms a polypeptide loop that covers the protein surface over the FeMo-cofactor; as this region has been suggested to participate in the interaction between Fe-protein and MoFe-protein, the presence of this additional protein segment could interfere with, or alter, complex formation between these proteins isolated from different sources.

\section{GENETICS AND ASSEMBLY OF THE NITROGENASE PROTEINS}

The complexity of the nitrogenase protein structures is reflected in the rather large number of genes in the nif regulon. Besides the three genes for the subunits of Fe-protein (nifH) and MoFe-protein (nifD and nifK for the $\alpha$ and $\beta$ subunits, respectively), at least 17 other genes have been identified and sequenced (reviewed in 57); depending on the species, the number of genes may be considerably greater than 20 . Several of the nif genes (nifA and nifL) are part of the regulatory mechanism that allows the expression of nitrogenase only when ammonia is depleted and, in some species, when the organism is growing anaerobically. Also encoded are flavodoxin (nifF) and, depending on the species, a pyruvate dehydrogenase (nifJ), the so-called "phosphorylclastic" enzyme, that catalyzes pyruvate conversion to acetyl phosphate concomitant with ferredoxin reduction. The phosphorylclastic reaction coupled to ferredoxin reduction provides both the electrons and the ATP required by nitrogenase.

The most important genes from the point of view of the functioning nitrogenase are those encoding processing enzymes. One of the earliest biochemical genetics contributions to nitrogenase chemistry was the recognition that mutations at loci other than the structural genes resulted in inactive enzymes. One of these mutants, UW45, had a MoFe-protein that could be activated by the acid extract of active, wild-type MoFe-protein (58). The purified activating material had the $S=3 / 2 \mathrm{EPR}$ signature of the 
wild-type protein and had a composition equivalent to all the molybdenum and approximately half the iron and inorganic sulfur $(59,60)$. This material, designated FeMo-cofactor, was subsequently determined to contain homocitrate by Ludden, Shah, and coworkers using elegant, classical biochemical methods (61). To date, five proteins, all encoded by the nif regulon, have been identified as essential for the assembly of cofactor (62). Two genes (nifE, nif $N$ ) encode subunits for a protein with substantial sequence homology to the MoFe-protein, including the ligand Cys- $\alpha 275$ and some of the residues that interact with the cofactor in the MoFe-protein (63). However, there are several critical residues that are not conserved, including three of the P-cluster pair cysteinyl ligands and the cofactor ligand His $\alpha 442$. The working hypothesis is that NIFE, $\mathrm{N}$ forms a scaffolding protein on which the cofactor is at least partially assembled before transfer to the des-FeMocofactor protein (64). Another required protein is the gene product of nifV, which appears to be homocitrate synthetase (61). In the absence of this enzyme, citrate is incorporated in place of homocitrate, with the resulting cofactor able to support reduction of most substrates, except dinitrogen (65). The function of nifB, the locus defined in UW45, has yet to be determined. Finally, the gene product of nifH is required. Because nifH encodes the $\mathrm{Fe}$-protein, one would assume that Fe-protein functions similarly to that in nitrogenase turnover, namely as an ATP-dependent redox donor. This is unlikely to be the case, however. Several mutant strains have been generated with Fe-proteins that are unable to hydrolyze ATP or to support ammonia production, yet which have normal MoFe-protein. Perhaps one clue to the role of Fe-protein in MoFe-protein assembly is the observation that desFeMo-cofactor protein from nifH $H^{-}$strains is poorly activated by isolated FeMo-cofactor, while des-FeMo-cofactor protein from the other nif strains can be (66-69). This implies that the des-FeMo-cofactor protein must be acted on by Fe-protein. One possibility for this requirement is the need to phosphorylate the des-FeMo-cofactor protein. This behavior could explain the difference in electrophoretic mobility of the protein, depending upon from what genetic background the des-FeMo-cofactor protein was isolated (68-70).

The insertion of the metal centers into apo-MoFe-protein also provides several perplexing problems. The des-FeMo-cofactor protein contains the P-cluster pairs, yet the analogous des-P-cluster pair protein has not been observed (69). No genetic loci have been specifically ascribed to assembly and/or insertion of the P-cluster pair. The most likely explanation is that the $\alpha$ and $\beta$ subunits can only assemble around the P-cluster pairs, and that the subunits serve as the scaffolding and final processing center for introducing the unique structural changes to the more conventional $4 \mathrm{Fe}: 4 \mathrm{~S}$ clusters. From chemical modification studies, it has been suggested that 


\section{8}

HOWARD \& REES

most of the holoenzyme three-dimensional structure is intact in the desFeMo-cofactor protein (J Magnuson and JB Howard, in preparation), including the Fe-protein docking site (see below for discussion of the docking mechanism). Although the cofactor pocket is deeply buried, the pocket is located at the interface of the three large $\alpha$ subunit domains, and could be exposed by as little as a $15-20^{\circ}$ rotation of the carboxy-terminal domain (JB Howard, unpublished). One role of Fe-protein in MoFe-protein assembly might be to stabilize these altered conformations apparently necessary for cofactor insertion.

The Fe-protein also requires processing for full activity. Although apo-Av2 can be reconstituted using inorganic $\mathrm{Fe}$ and $\mathrm{S}^{2-}$ salts, the resulting activity is highly variable (71). Recently, Dean and coworkers have reported (72) that nifS encodes a sulfuryl transferase which, in combination with apo-Av2, regenerates full activity of Fe-protein (D Dean, personal communication). nifS is one of several genes that are not absolutely required for biosynthesis of active nitrogenases, presumably because similar enzymes are expressed in cells as part of a more general need to synthesize proteins containing iron-sulfur clusters. In contrast, nifM is essential for active Fe-protein (73, 74). The function of NIFM is unknown, except that it is not directly involved in cluster synthesis or insertion. It should be noted that Fe-protein from nif $^{-}$strains is still fully active in FeMo-cofactor synthesis (34).

Finally, some prokaryotic species contain other, so-called alternate, forms of nitrogenase in addition to the conventional, molybdenum-containing proteins, which are expressed under various conditions of molybdenum depletion (reviewed in $(75,76)$ ). The amino acid sequences of the alternate nitrogenases are nearly identical to the conventional proteins. The most interesting feature of the alternate enzymes is the lack of molybdenum, which is apparently replaced by either vanadium or iron. Indeed, cofactors extracted from these proteins have only iron or vanadium and iron, yet will substitute for FeMo-cofactor in the UW45 reconstitution assay. Although several genes are common to the alternate and conventional nitrogenase systems, the structural genes are different, and there are additional control elements for regulating expression.

\section{MECHANISM OF NITROGENASE}

Often the nitrogenase mechanism is intellectually divided into two parts, the redox cycle between the Fe-protein and the MoFe-protein, and the substrate reduction cycle. Although this framework has been useful for obtaining some of the individual reaction rates, we attempt to integrate the two cycles with the new molecular structures. The salient, experimental observations that must be accounted for by a mechanism may be summarized: 
1. Electron transfer proceeds from the Fe-protein to the MoFe-protein. 2. Two ATP are hydrolyzed per electron transferred at maximum efficiency. 3. Although ATP and ADP are bound by the Fe-protein, only the Fe-protein/MoFe-protein complex turns over ATP; Fe-protein-MgATP does not. 4. The rate of substrate reduction is dependent on both the ratio of the two protein components and the absolute protein concentration. 5. Various salts are inhibitors of the substrate reduction activity. 6 . There is a burst of ATP hydrolysis before substrate reduction. 7. At a fixed concentration and ratio of protein components, electron flux is independent of which substrate is reduced. 8. Carbon monoxide is an inhibitor of all substrate reduction except for protons. Two additional observations are less convincingly documented yet are generally accepted conditions. 9. The direction of electron transfer in the MoFe-protein is from the P-cluster pair to the FeMo-cofactor. 10. All substrates are reduced at the cofactor [with the possible exception of some reduction of $\mathrm{H}^{+}$to $\mathrm{H}_{2}$ at the P-cluster pair (17)].

\section{Redox Cycle}

Hageman \& Burris (77-79) first proposed that only one electron-transfer event occurs before dissociation of the Fe-protein/MoFe-protein complex. Because all nitrogenase substrates require multiple electrons, several cycles of complex formation and dissociation must occur before product formation. This concept was expanded by Thorneley \& Lowe (80) who, from presteady-state and turnover reaction kinetics, determined that at saturating Fe-protein ratios, the overall rate-determining step was the dissociation of Complex II (controlled by the rate constant $\mathrm{k}_{-3}$ ). An expanded version of the Thorneley-Lowe model is shown in Figure 7. Implicit in this conclusion is that oxidized and reduced Fe-protein $[\mathrm{AXP}]_{2}$ complexes have different affinities for MoFe-protein; the corollary is that the two Fe-protein forms must have different conformations. The cyclic process also accounts for the dependence of the substrate reduction rate on both the total protein concentration and the ratio of the two proteins, since both factors contribute to the concentration of Complex I. The pronounced salt inhibition of substrate reduction has been explained as a simple competitive inhibition of complex formation as indicated Figure 7 (81). Although the inhibition is kinetically equivalent when applied to either protein component, Diets \& Howard (81) chose to emphasize salt binding to the Fe-protein, because the strong salt inhibition of ATP-dependent iron chelation from Fe-protein implies a direct effect on this component. A final important facet of the cycle is that ATP hydrolysis appears to precede electron transfer (82). For purposes of this discussion, the single, fast, ATP hydrolysis-coupled electron-transfer step of the Thorneley-Lowe model has been separated into two distinct events: hydrolysis of ATP and electron transfer. 


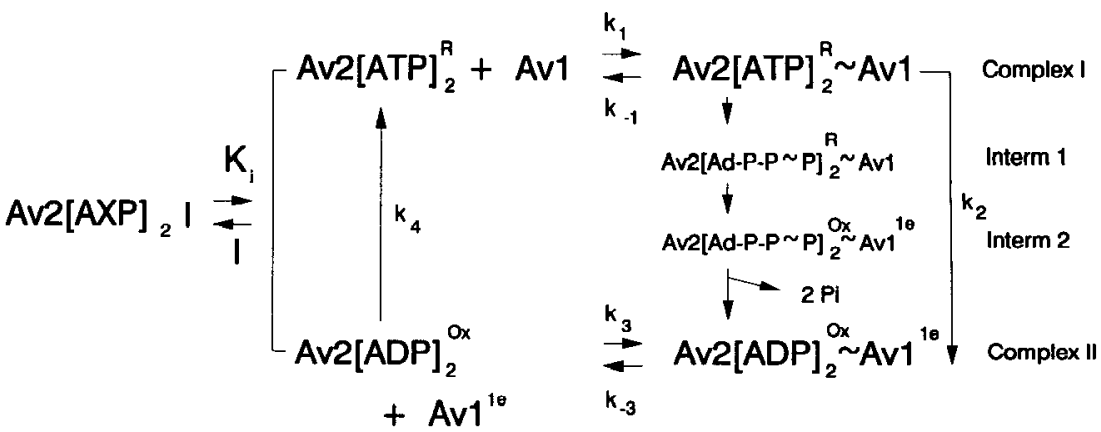

Figure 7 Single redox cycle for nitrogenase turnover using the $A$. vinelandii proteins as an example (77-81). Avl is depicted as undergoing a one-electron reduction. Intermediates 1 and 2 are hypothetical stages on the path for electron transfer coupled to ATP hydrolysis. It is assumed that hydrolysis of at least one ATP precedes electron transfer. Both intermediates are considered as metastable states in which ATP is hydrolyzed without the release of inorganic phosphate (Pi). Whether both ATP are hydrolyzed at the same time or sequentially is unknown. Salt (I) inhibition is shown as a complex with either oxidation state of Av2, and with either nucleotide or no nucleotide bound (81).

The Hagerman-Burris-Thorneley-Lowe model has made a significant contribution to our concept of the nitrogenase mechanism and predicts many of the observed properties $(77,80)$. With the availability of altered proteins with site-specific amino acid substitutions, many of the original assumptions about the mechanism can be reconsidered. For example, the Thorneley-Lowe (80) assumption that $50 \%$ of the Fe-protein is inactive, yet can compete kinetically with the active form, should be reconciled with the observation that inactive and low-activity mutant proteins fail to compete kinetically, even though they can be chemically crosslinked to the MoFe-protein (34, 39-41, 83-85). Likewise, the assumption that all Fe-protein to MoFe-protein electron transfer rates are the same can be tested, as well as the hypothesis that the rate of proton reduction does change with the redox state of the MoFe-protein. Finally, the effects of salts on the individual first- and second-order rates are largely unknown. The observed overall inhibition of substrate reduction by salts (81) needs to be reconciled with the fact that the rate-determining step is increased by salts (80). The Diets \& Howard (81) treatment of salt inhibition may be an oversimplification, and a detailed analysis of the effect of salts on each step in the Thorneley-Lowe model is needed.

\section{Role of ATP Hydrolysis}

One of the primary, unanswered questions for understanding the nitrogenase reaction is how MgATP hydrolysis is coupled to electron transfer. It is important to keep in mind that there is no inherent thermodynamic requirement for ATP hydrolysis in substrate reduction, e.g. the redox potential of 
the Fe-protein at $-380 \mathrm{mV}$ is below that for hydrogen evolution at $\mathrm{pH}<$ $\sim 7$. Likewise, only the first step of nitrogen reduction (breaking the first bond in dinitrogen triple bond to form diimide) has a lower redox potential than does Fe-protein, so that most electron transfer steps along the reaction pathway should be thermodynamically favorable (4). Consequently, it appears that ATP must be required for kinetic reasons, such as controlling a conformational gate, that ensures quasi-unidirectional electron transfer.

Related to the question of how ATP is utilized is the perplexing problem of how the putative electron acceptor in the reaction, the P-cluster pair, can be reduced. First, it appears that all the iron sites in the P-cluster pairs are already in the reduced ferrous state, leaving only the disulfide bridge as an acceptor. Long-distance, outer-sphere electron transfer would seem unlikely for the disulfide reduction because (a) the bridging cysteinyl ligands constrain the linked $4 \mathrm{Fe}: 4 \mathrm{~S}$ segments too closely (by $\sim 1 \AA$ ) to accommodate nonbonded contact between reduced cluster sulfurs, and $(b)$ disulfide reduction usually proceeds by inner-sphere chemical coupling such as disulfide exchange and in activated carbon adducts. Consistent with this view, it has not been possible, for example, to reduce the P-cluster pair in the isolated $\mathrm{MoFe}$-protein by either low-molecular-weight reductants or by electrochemical methods. In contrast, the P-cluster pairs can be oxidized by dyes, demonstrating that these cofactors are electrochemically accessible. The second problem is that the one electron per FeMo-cofactor reduced state of the MoFe-protein has the electron on the cofactor, and not on the P-cluster pair, i.e. the cofactor becomes EPR silent (87). At least in the generation of this form of MoFe-protein, any proposed reduced P-cluster pair must exist transiently at best.

Thus, the role of ATP in electron transfer may be even more complex than has been generally appreciated. One plausible explanation is that conformational changes associated with ATP binding and hydrolysis might be utilized in two alternate ways: 1 . to induce conformational changes in the MoFe-protein required for electron transfer from the P-cluster pair to the cofactor and 2. to induce conformational changes in Fe-protein required for electron transfer to the P-cluster pair. This hypothesis requires that conformational changes occur in the MoFe-protein as well as in the Fe-protein during the complex formation. The critical event in the process is the reorganization at the P-cluster pair such that it can become a better redox acceptor/donor. This is accomplished only by formation of the active complex between MoFe-protein and Fe-protein. The unique and probably essential property of the P-cluster pair is to act as the gate for electron transfer from the Fe-protein to the FeMo-cofactor. As stated above, in the resting state (whose structure presumably has been determined by X-ray diffraction), the cluster disulfide is unlikely to be a good electron acceptor. 


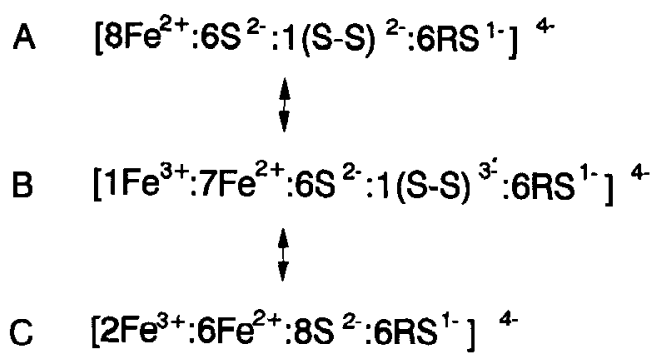

Figure 8 Three-state hypothesis for internal redox states of the P-cluster pair.

However, as a consequence of a Fe-protein-induced conformational change, an electron could be transferred from the P-cluster pair to the cofactor, prior to reduction of the former by the Fe-protein. The resulting one-electron oxidized P-cluster pair would now be a good acceptor. In addition, once the physical restraints on the cluster were relaxed, the P-cluster pair could undergo internal redox chemistry as outlined in Figure 8. In this scheme, the disulfide (state A) could be reduced to either a disulfide radical (state $B$ ) or to inorganic sulfide (state C) by internal inner-sphere chemistry of the ferrous ligands, without net reduction of the cluster. In either state B or $\mathrm{C}$, electrons could be donated to the FeMo-cofactor or accepted from the Fe-protein by outer-sphere, long-distance transfer mechanisms usually envisioned for two redox-coupled clusters. This model satisfies the observed electronic states of the clusters and the unique requirement for Fe-protein as the reductant, i.e. only the Fe-protein can serve as the key required to unlock the necessary conformational changes in MoFe-protein that allow electron transfer from the P-cluster pair to the FeMo-cofactor. The net result of the scheme is to have the P-cluster pair in the same oxidation state at the beginning and the end of the redox cycle, while the FeMo-cofactor and Fe-protein are reduced and oxidized, respectively, by one electron.

\section{Complex Formation and ATP Hydrolysis}

The minimum requirements for formation and turnover of a kinetically competent complex must include the following conditions. 1. Intimate and precise orientation of the two nitrogenase components must precede electron transfer and, as suggested above, at least some differences in Complexes I and II must exist. 2. In Complex I, the MoFe-protein must induce the changes in Fe-protein necessary for ATP hydrolysis. That is, there must be some signal sent from the MoFe-protein to the Fe-protein nucleotide site. 3. During the transition between the ATP and ADP states, the protein 
components must undergo conformational changes that lead to the correct alignment of the respective donor and acceptor pairs. As discussed above, both proteins may undergo such changes. 4. After electron transfer to the MoFe-protein, the complex must relax sufficiently so that electron transfer back to the oxidized Fe-protein is rare.

The inhibitory effects of salt on enzyme activity $(81,83,88)$ and on chemical crosslinking $(89,90)$ support the idea that ionic interactions contribute to these complexes. The results with several altered Fe-proteins, primarily involving substitutions for Arg100, suggest there are several different classes of ionic interactions, some contributing more than others (83). Chemical crosslinking with the water-soluble carbodiimide is highly specific between Glu 112 of Av2 and Lys $\beta 400$ of Av1. Interestingly, Glu112 is part of an acidic patch of seven carboxylic acid residues at the end of the long helix extending from the cluster in both subunits. At the other end of this helix, next to the cluster, is Arg 100. Thus, the two well-characterized ionic regions implicated in complex formation are on the same surface as the cluster (Figure 9).

Potential docking modes for the Av2 and Av1 structures have been presented that superimpose the molecular two-fold axis of Av2 and the pseudo-two-fold axis of Avl (15). A groove in the "crown" above the P-cluster pair can begin to accommodate the extended $\alpha$-helices that frame the Av2 4Fe:4S cluster (Figure 10). In this orientation, the side chains of Glu112 and Lys $\beta 400$ are juxtaposed, but are $\sim 8 \AA$ apart, too far for the rapid and specific crosslinking reaction to proceed. Likewise, Lys $\alpha 50$ and Lys $\alpha 51$ are positioned near Glu112 on the symmetrically related Av2 helix. Formation of a crosslink at this site would appear to be as probable as for Lys $\beta 400$ on the other side, but experimentally this does not occur. Although crosslinking is strictly dependent on having a native structure in the proteins, it does not require nucleotide. These results suggest a specific, preliminary association in which crosslinking precedes the more symmetrically superimposed two-fold axis state (see Figures 9 and 10; Ref. 86).

In the symmetrical "helix in the groove" orientation, the Fe-protein cluster and the P-cluster pair are separated by a distance $>16 \AA$ at van der Waals contact between the two proteins. A large number of ionic interactions between the two proteins are possible, with one notable exception. Namely, the critical residue Arg100 of Fe-protein cannot reach any acidic residue on the MoFe-protein-docking face. The consequence of this is considered further below. In addition to the ionic interactions, there are several potentially important hydrophobic interactions. Phe- $\alpha$ and $\beta 125$ of the MoFe-protein can interact with the hydrophobic residues 102-109 that are part of the two surface helices on the Fe-protein. At contact, these Phe side chains could fit into pockets created by Ile103 and Thr104 and connected 

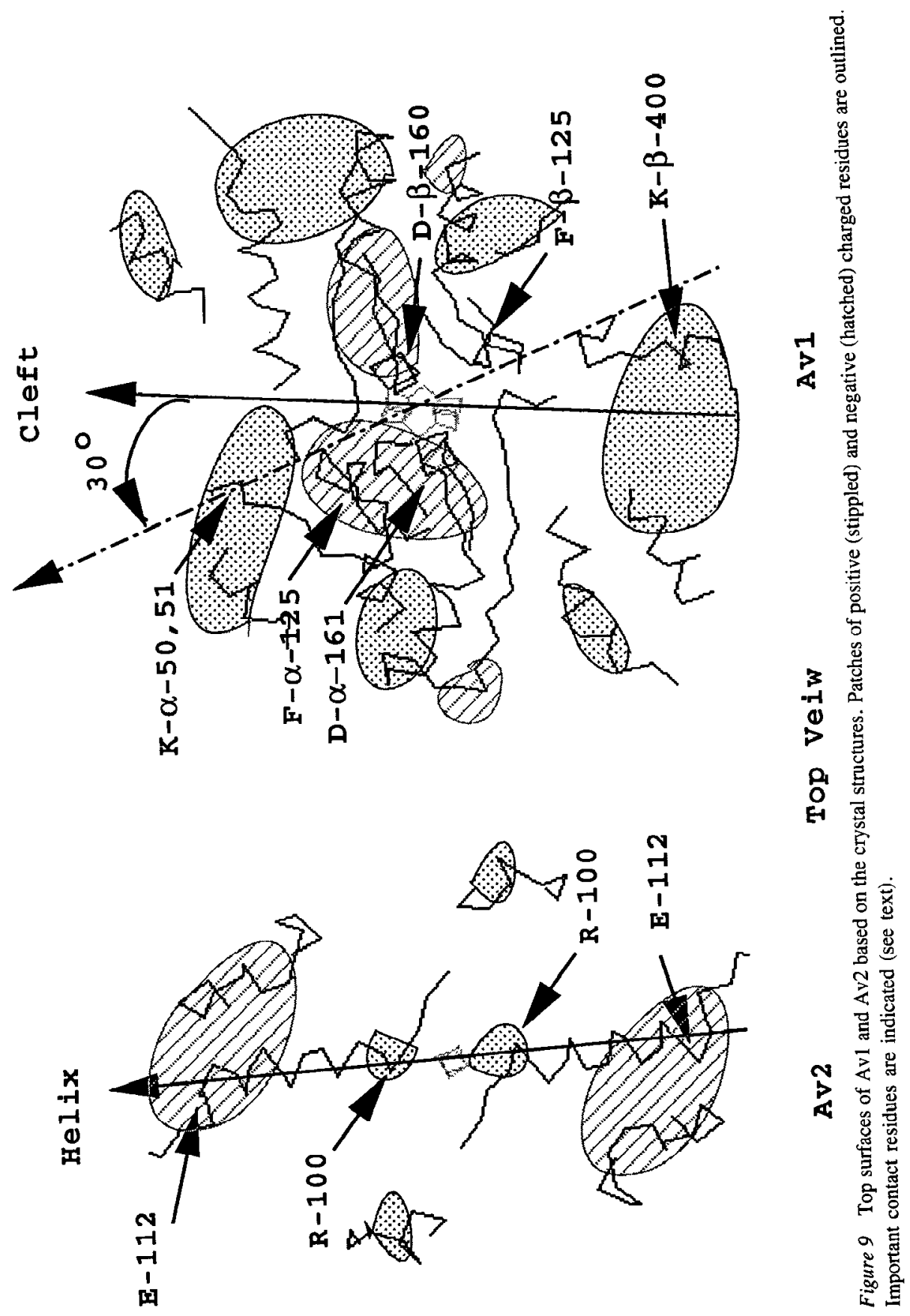


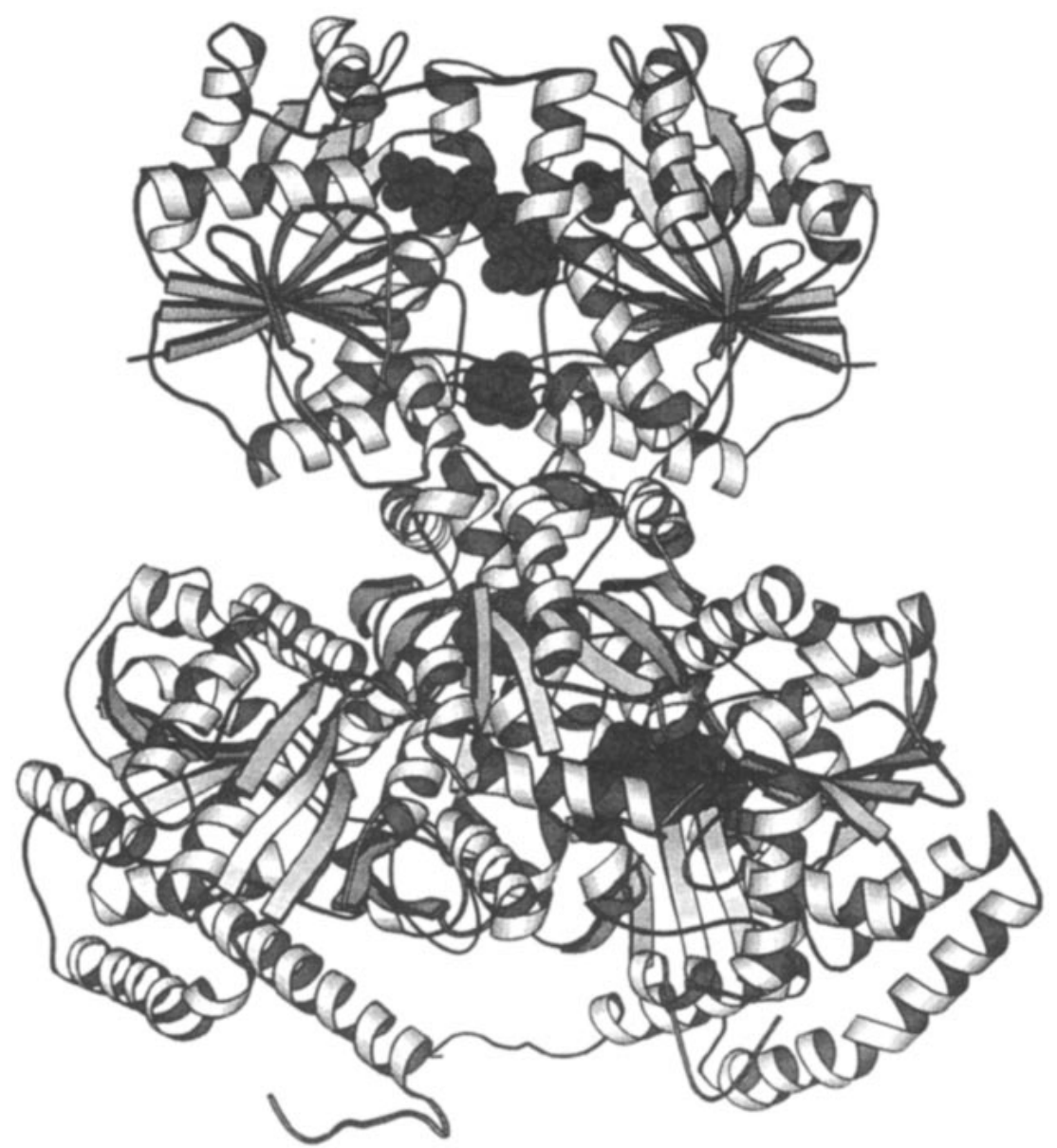

Figure 10 Ribbons diagram of a computer-generated model of the docking complex between $\mathrm{Fe}$-protein (top molecule) and an $\alpha \beta$ subunit pair of the $\mathrm{MoFe}$-protein (bottom). The metal centers and ADP molecule are represented by space-filling models. Prepared with the program MOLSCRIPT (36a) and reproduced with permission from (8a).

to Val102 of Fe-protein which, in turn, interacts with a $\beta$-sheet below the Fe-protein surface at Cys38 (see Figure 11). Substitution of Ser for this internal Cys 38 has profound effects on the ATP requirement, with a $\sim 50$-fold decrease in the efficiency of ATP hydrolyzed per electron transferred (J Magnuson and JB Howard, in preparation). As shown in Figure 11, the amide backbone hydrogen bonds from Cys 38 to Asp125 completes a direct 


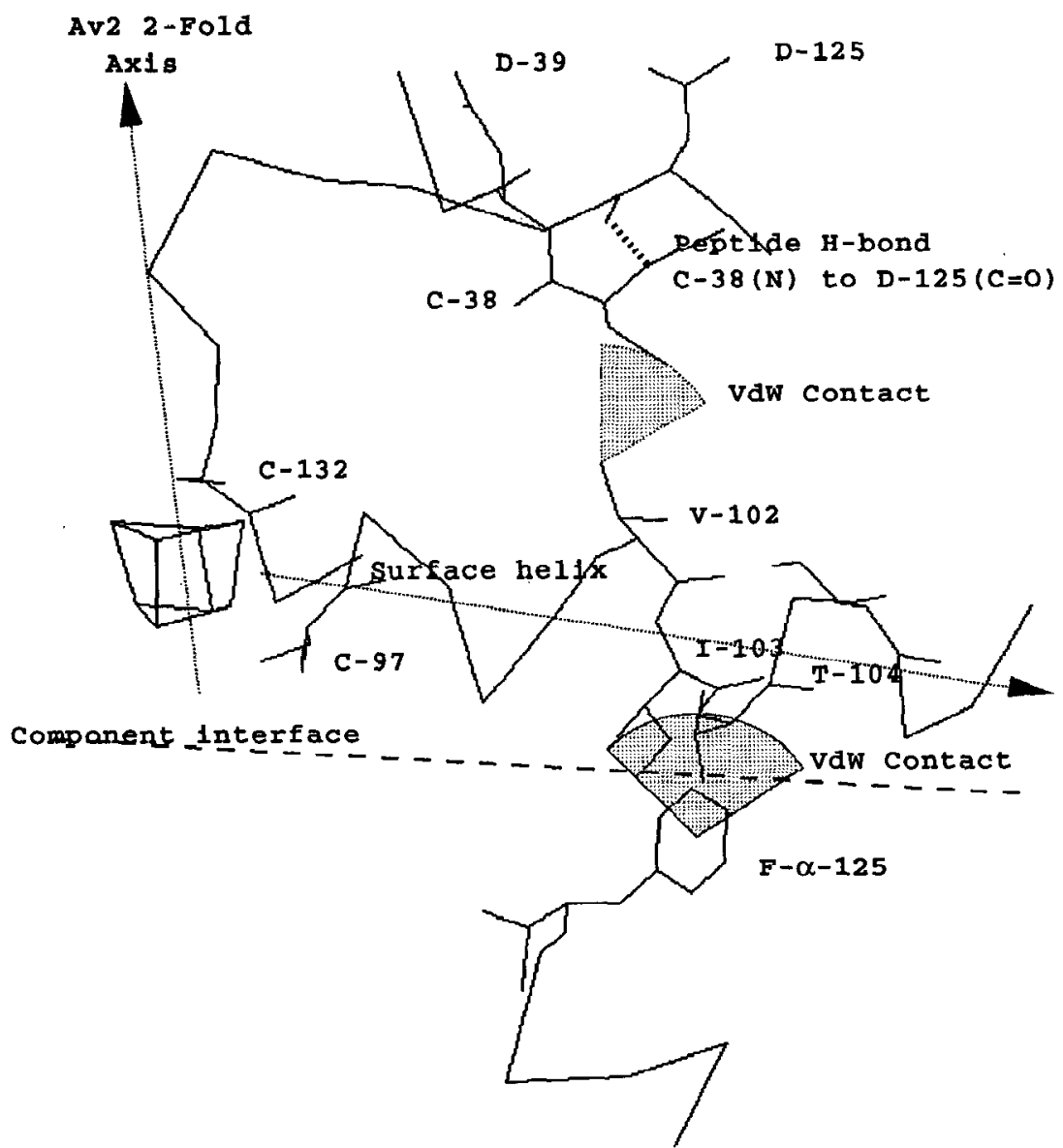

Figure 11 Proposed pathway linking the interaction of Phe $\alpha 125$ of Av1 to the nucleotide-binding site in Av2. A symmetrically related interaction between Phe $\beta 125$ and the second Av2 subunit is not shown for clarity of presentation. The $\alpha$-helix from cluster ligand Cys 97 to Glu112 on the surface of Av2 is positioned over a second helix (not shown) that includes Cys38 and Asp39, and interacts with that helix through van der Waals contact between Cys38 and Val102. A $\beta$-strand containing Asp125 and a bend leading to the cluster ligand, Cys132, are connected to Cys 38 by an amide hydrogen bond.

link between the MoFe-protein contact site and the nucleotide- and $\mathrm{Mg}$ binding sites. The potential importance of Phe $\beta 125$ of the MoFe-protein has been verified by substitution by several hydrophobic residues (91), some of which have considerably lower turnover rates and increased nucleotide 
affinity in turnover. Hence, the ATP hydrolysis signal from the MoFe-protein may follow this path.

For more intimate contact allowing the $4 \mathrm{Fe}: 4 \mathrm{~S}$ cluster and P-cluster pair to approach to $<15 \AA$, the groove in the crown must be opened. An approximately $30^{\circ}$ rotation of the Fe-protein would force the groove open, allowing new ionic interactions (Figure 9). Importantly, the two Arg100s (from the two symmetrically related Fe-protein subunits) can form salt bridges with Asp $\alpha 160$ and Asp $\beta 161$. These two invariant acidic residues are located on helices connected to cysteinyl ligands of the P-cluster pair. Thus, in addition to bringing the two clusters closer together, the model building shows that the rotation would affect the environment of the P-cluster pair directly. The rotation in the cleft would be a true "work" step, which could be driven by reorientation of the Fe-protein subunits in response to ATP hydrolysis. A metastable complex similar to Intermediate 1 in Figure 7 can be envisioned, where the ATP is hydrolyzed, but the inorganic phosphate has not been released. After the electron transfer, the phosphate dissociates and the system relaxes when the Fe-protein achieves the MgADP conformation leading to Complex II.

A mechanism for utilizing the hydrolysis of ATP to drive conformational transitions has been proposed, based upon the two potential binding modes for nucleotides in Av2 (41, 86; see Figure 12). In this hypothesis, MgATP is bound in the ras-like mode parallel to the two-fold axis separating the subunits. The residue analogous to Asp125 in ras p21 (Asp57) is hydrogen bonded to a water in the coordination sphere of the $\mathrm{Mg}(21,22)$. After hydrolysis, the water is displaced and the aspartyl residue is liganded directly. The shift causes a movement along the attached helix-turn which, in the case of Av2, leads directly to Cys132, the bottom ligand of the Fe:S cluster. It is tempting to complete the picture of the conformational changes by suggesting that the purine ring moves to the ADP-binding mode perpendicular to the two-fold axis and the subunits contract. Two observations indicate that this hypothesis is more than just fantasy. First, in the presence of ADP and ATP, the ligands on the $4 \mathrm{Fe}: 4 \mathrm{~S}$ cluster are clearly in different environments as detected by proton NMR spectroscopy (JB Howard, unpublished), suggesting some reorientation of the subunits occurs. Second, only in the ras-like ATP-binding mode is the $\gamma$-phosphate correctly positioned for water attack, assisted by Asp39 and/or Asp129, the likely candidates for the general base in hydrolysis (Figure 12). Notice that Asp39 is also likely to sense the MoFe-protein binding by the path involving its neighbor, Cys 38 (Figures 11 and 12), while Asp129 could be effected by the polypeptide connection to Asp125. It should be noted that Asp129 in Fe-protein is analogous to Gln61 in ras, a candidate general base for GTP hydrolysis. 


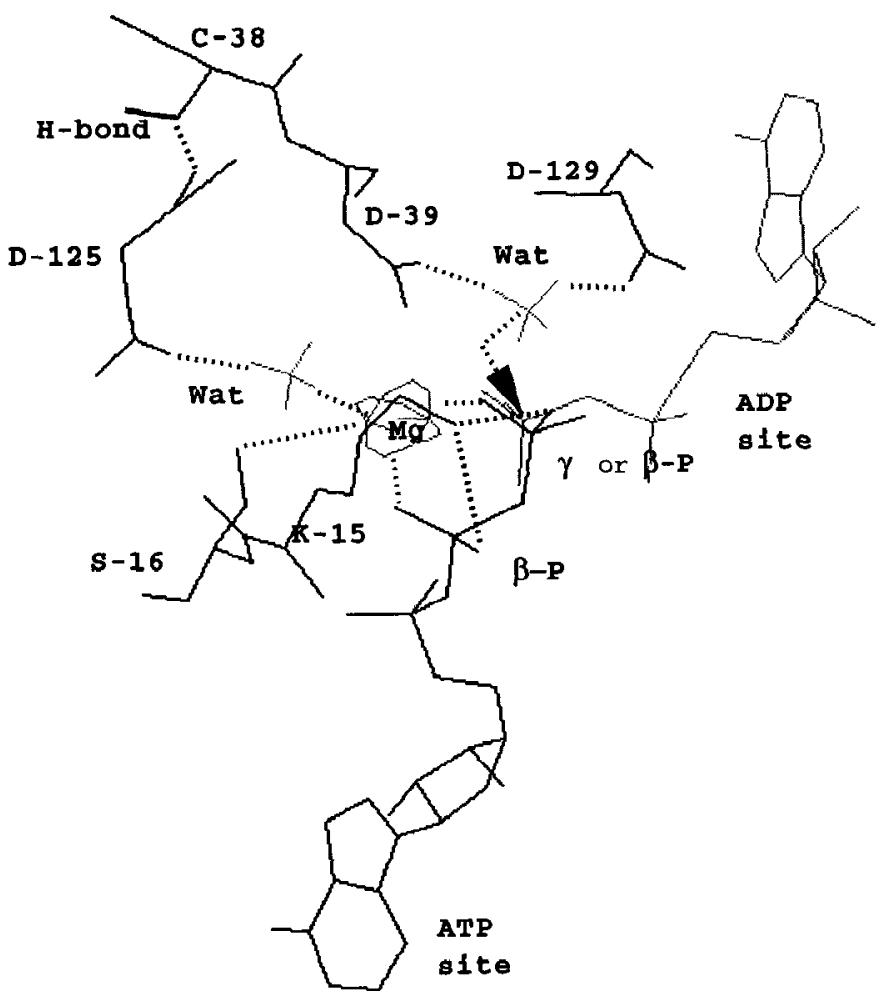

Figure 12 Hypothetical arrangement of ATP, $\mathrm{Mg}$, and two water (Wat) molecules in the Av2 structure based upon comparison to ras p21 (21). ADP is shown as observed in the Av2 structure, with superposition of Lys 15 of Av2 and Lys 16 of ras $\mathrm{p} 21$. With this superposition, the $\gamma$-phosphate of ATP in the "ras"-binding mode is only $\sim 0.2 \AA$ displaced from the $\beta$-phosphate of ADP. A water molecule hydrogen bonded to Asp1 25 is included as ligand of $\mathrm{Mg}$, as observed in ras $\mathrm{p} 21$. A second water molecule is placed, again by comparison to ras p21, for attack on the terminal phosphate of ATP, assisted by Asp39 and/or Asp129.

\section{Electron Transfer and Substrate Reduction}

The distance of closest approach between metal sites in the P-cluster pair and the FeMo-cofactor is $\sim 14 \AA$, which suggests that the electron transfer rate between these centers could be faster than the rate of nitrogenase turnover $(92,93)$. The rate of this electron transfer would determine the lifetime of a reduced or oxidized P-cluster pair: i.e. whether or not such a species would exist transiently or long enough to probe spectroscopically (if this species exists at all). Potential electron-transfer pathways between 
these centers have been described $(15,19)$; in particular, the helices $\alpha 63-\alpha 74$ and $\alpha 88-\alpha 92$ adjacent to the P-cluster pair ligands Cys $\alpha 62$ and Cys $\alpha 88$ are directed towards the FeMo-cofactor. The locations of homocitrate and the Mo on the side of the FeMo-cofactor closest to the P-cluster pair suggest that these groups might also participate in electron transfer between these two redox centers.

The structural details of substrate binding to the FeMo-cofactor and the sequence of electrons and protons transferred to the bound substrate are critical questions. In addition to dinitrogen and protons, nitrogenase stereospecifically reduces a variety of substrates, including acetylene, azide, cyclopropene and 1-butyne, all of which, except for protons, are inhibited by CO. Significantly, the rate of electron flow through the nitrogenase system, under a given set of conditions, is independent of the substrate reduced $(94,95)$. In the absence of $\mathrm{N}_{2}$ or in the presence of $\mathrm{CO}$, for example, the entire electron flux can be funneled into reduction of protons to $\mathrm{H}_{2}$, which occurs at the same rate (per electron) as if $\mathrm{N}_{2}$ were present or $\mathrm{CO}$ absent. Under conditions where the rate of electron flux through nitrogenase is decreased (by lowering the concentration of external reductant or Fe-protein, for example), the proportion of hydrogen and other products requiring fewer electrons increases at the expense of products requiring more electrons. These observations suggest that electron transfer from Fe-protein to MoFe-protein is independent of substrate binding to the FeMo-cofactor.

Since all known substrates of nitrogenase are reduced by an even number of electrons (and, almost always, require an equivalent number of protons), most mechanistic schemes have focused on addition of one (or more) pairs of electrons to dinitrogen, leading to the formal reduction sequence: dinitrogen, diimide, hydrazine, and ammonia. The major barrier in this case should be the two-electron reduction of dinitrogen to diimide. One interesting possibility is that this barrier could be sidestepped by a four-electron reduction process, reducing dinitrogen directly to the hydrazine oxidation level. This could be achieved, for example, by a combination of a twoelectron donation from the P-cluster pair (possibly involving sulfide-disulfide conversion), coupled with two electrons stored in the FeMo-cofactor. Funneling of the requisite number of protons into the buried active center is also a critical process during substrate reduction; various ionizable groups in the vicinity of the FeMo-cofactor and the presence of an extensive water network near the homocitrate may participate in this process.

In the absence of any experimental evidence indicating how substrates might bind to the FeMo-cofactor, a range of hypothetical models have been proposed $(17,96,97)$. Binding interactions between substrates and one or more of the $\mathrm{Fe}, \mathrm{Mo}$, and/or $\mathrm{S}$ sites are all conceivable, and at this stage, it would seem prudent not to dismiss any potential candidates. Definitive 
experimental information concerning the structure(s) of substrate(s) bound to FeMo-cofactor will be essential for formulating more detailed mechanisms concerning the reduction and protonation reactions.

Two basic types of experiments have been conducted to probe the functional significance of groups surrounding the FeMo-cofactor: site-directed mutagenesis, and replacement of homocitrate with various carboxylic acids. Other than replacement of the cofactor ligands (which results in loss of cofactor and activity), His $\alpha 195$ and Gin $\alpha 191$ have been the most mutagenized targets $(98,99)$. Substitution of His $\alpha 195$, which is hydrogen bonded to one of the bridging sulfurs of the FeMo-cofactor, by Asn, Gln, Thr, Gly, Leu, or Tyr, results in a Nif ${ }^{-}$phenotype, i.e. the organism is no longer capable of diazotrophic growth. More varied Nif phenotypes are found with substitution of Gln $\alpha 191$. The side chain of this residue is hydrogen bonded to both a carboxyl group of homocitrate and the NH of residue $\alpha 61$ (adjacent to the P-cluster pair ligand $\alpha 62$ ), and hence is positioned between the cofactor and the P-cluster pair. While some substitutions, such as GIn to Lys, result in Nif ${ }^{-}$phenotype, others, such as Gin to Ala or Pro, support diazotrophic growth rates comparable to wild type. These latter observations are particularly surprising, since these side chains cannot participate in the hydrogen-bonding interactions exhibited by the Gln side chain. Preliminary reports of mutagenesis experiments of residues Arg $\alpha 96$, Arg $\alpha 359$, Phe $\alpha 381$, and Gln $\alpha 440$ in the vicinity of the cofactor have also appeared (99).

The function of homocitrate in nitrogenase is intriguing, given that it is coordinated to the Mo, is surrounded by a number of buried water molecules, and is on the side of the cofactor nearest to the P-cluster pair. To probe the role of homocitrate, Ludden \& Shah have pioneered the development of in vitro methods for substituting other organic acids for homocitrate in the FeMo-cofactor (100). In general, the minimal requirements for functional activity by homocitrate substituents include two carboxyls and a hydroxyl group. The specific stereochemistry of the organic acid can also profoundly influence the ability of this group to support reduction of various substrates by nitrogenase. An example of this behavior is provided by the replacement of homocitrate with either erythro-fluorohomocitrate or threo-fluorohomocitrate (101). These compounds are substituted with a single fluoro group on the single methylene-containing arm of homocitrate, which links the Moliganding groups to the carboxyl that hydrogen bonds to Gln $\alpha 191$. While the erythro-fluorohomocitrate-substituted FeMo-cofactor has high activities in most nitrogenase activities (including $\mathrm{N}_{2}$ reduction), the threo-isomer has very low $\mathrm{N}_{2}$ reduction activity, although it has more normal levels of acetylene and proton-reduction activities. Examination of the crystal structure shows that, without any rearrangement, a threo-substituent would be directed 
towards the cofactor and would be in close contact with one of the cluster sulfurs, while an erythro-substituent would point away from the cofactor. Apparently, the proximity of the threo-fluoro to the cofactor could drive a rearrangement of this region that results in altered activity, while the erythro-fluoro group can be accommodated without any mechanistically significant changes. Alternatively, in view of the acidity of these methylene protons in homocitrate, substitution of a hydrogen by fluorine may block stereospecific transfer of one of the hydrogens to the cluster, during a putative step in protonation of bound substrate.

It should be noted that characterization of nitrogenase variants, which is central to understanding the functional roles played by a residue, is far from a trivial matter. The complexity of this problem is illustrated by observations that while certain variants cannot reduce dinitrogen to ammonia, some of them can still reduce protons and/or acetylene (including the production of ethane from acetylene, a reaction that is not catalyzed by the wild-type enzyme), or exhibit altered responses to inhibition by $\mathrm{CO}$ and/or other ligands. Mutations in the Fe-protein have exhibited altered coupling between ATP hydrolysis and electron transfer, pronounced changes in nucleotide and metal requirements, substantial increases in salt sensitivity, as well as altered biophysical/spectral properties. It is essential that each variant be characterized as thoroughly and carefully as possible, to obtain the most complete understanding of the functional consequences associated with an amino acid substitution.

\section{RELATIONSHIP OF NITROGENASE TO OTHER SYSTEMS}

From a protein structural perspective, nitrogenase provides a tantalizing combination of protein-protein interactions and conformational changes coupled to ATP hydrolysis. The coupling between nucleotide-binding and redox behavior of Fe-protein not only is an important problem for the nitrogenase mechanism, but also is representative of a much broader biochemical phenomenon in which nucleotide hydrolysis is coupled to a second process, such as membrane transport, cellular regulation, or molecular motors (2126). A common theme that is emerging is that switching between alternate conformational states of a protein, driven by nucleotide binding and hydrolysis at the interface between different subunits or domains, provides a general transducing and timing mechanism for coupling the energy of nucleotide hydrolysis to a variety of biochemical processes. Sequence analyses by Koonin (102) suggest that the Fe-protein may represent an ancestral form of a now widespread assortment of nucleotide-binding proteins, so that the basic structural machinery utilized for transducing the 
energy of ATP hydrolysis in nitrogenase may have been recruited for a diverse range of other biological functions.

\section{ACKNOWLEDGMENTS}

The efforts and contributions of J. Kim, M. Georgiadis, D. Woo, M. K. Chan, M. W. Day, J. Schlessman, H. Komiya, L. Joshua-Tor, M. H. B. Stowell, B. T. Hsu and A. J. Chirino are deeply appreciated, as are discussions, sharing of preprints, etc with our nitrogenase colleagues. Research in the authors' laboratories was supported by grants from NIH and NSF.

Any Annual Review chapter, as well as any article cited in an Annual Review chapter, may be purchased from the Annual Reviews Preprints and Reprints service. 1-800-347-8007; 415-259-5017; email:arpr@class.org

\section{Literature Cited}

1. Ferguson SJ. 1988. In The Nitrogen and Sulphur Cycles, ed. JA Cole, SJ Ferguson, pp. 1-30. Cambridge: Cambridge Univ. Press

2. Burgess BK. 1984. In Advances in Nitrogen Fixation, ed. C Veeger, WE Newton, pp. 103-14. Boston: Martinus Nijhoff

3. Orme-Johnson WH. 1985. Annu. Rev. Biophys. Biophys. Chem. 14:419-59

4. Stiefel EI, Thomann H, Jin H, Bare RE, Morgan TV, et al. 1988. In Metal Clusters in Proteins, ed. L Que, pp. 372-89. Washington, DC: Am. Chem. Soc.

5. Smith BE, Eady RR. 1992. Eur. J. Biochem. 205:1-15

6. Burris RH. 1991. J. Biol. Chem. 266: 9339-42

7. Rees DC, Chan MK, Kim J. 1993. Adv. Inorg. Chem. 40:89-119

8. Stacey G, Burris RH, Evans HJ, eds. 1992. Biological Nitrogen Fixation. New York: Chapman \& Hall. 943 pp.

8a. Kim J, Rees DC. 1994. Biochemistry. In press

9. Simpson FB, Burris RH. 1984. Science 224:1095-97

10. Hausinger RP, Howard JB. 1982. $J$. Biol. Chem. 257:2483-90

11. Brigle KE, Newton WE, Dean DR. 1985. Gene 37:37-44

12. Lundell D, Howard JB. 1978. J. Biol. Chem. 253:3422-26

13. Georgiadis MM, Komiya H, Chakrabarti P, Woo D, Kornuc JJ, Rees DC. 1992. Science 257:1653-59
14. Kim J, Rees DC. 1992. Science 257: 1677-82

15. Kim J, Rees DC. 1992. Nature 360: $553-60$

16. Kim J, Woo D, Rees DC. 1993. Biochemistry 32:7104-15

17. Chan MK, Kim J, Rees DC. 1993. Science 260:792-94

18. Rees DC, Kim J, Georgiadis MM, Komiya H, Chirino AJ, et al. 1993. See Ref. 29, pp. 170-85

19. Bolin JT, Campobasso N, Muchmore SW, Minor W, Morgan TV, Mortenson LE. 1993. See Ref. 30, pp. 89-94

20. Bolin JT, Campobasso N, Muchmore SW, Morgan TV, Mortenson LE. 1993. See Ref. 29, pp. 186-95

21. Pai EF, Krengel U, Petsko GA, Goody RS, Kabsch WK, Wittinghofer A. 1990. EMBO J. 9:2351-59

22. Tong $\mathbf{L}$, de Vos AM, Milburn MV, Kim S-H. 1991. J. Mol. Biol. 217:50316

23. Riordan JR, Rommens JM, Kerem BS, Alon N, Rozmahel R, et al. 1989. Science 245:1066-72

24. Karkaria CE, Chen CM, Rosen BP. 1990. J. Biol. Chem. 265:7832-36

25. Rayment I, Rypniewski WR, SchmidtBäse K, Smith R, Tomchick DR, et al. 1993. Science 261:50-58

26. Story RM, Steitz. TA. 1992. Nature 355:374-76

27. Jurnak F. 1985. Science 230:32-36

28. Kjeldgaard M, Nyborg J. 1992. J. Mol. Biol. 223:721-42

29. Stiefel EI, Coucouvanis D, Newton 
WE, eds. 1993. Molybdenum Enzymes, Cofactors and Model Systems. Washington, DC: Am. Chem. Soc. 387 pp.

30. Palacios R, Mora J, Newton WE, eds. 1993. New Horizons in Nitrogen Fixation. Dordrecht: Kluwer Academic. $788 \mathrm{pp}$

31. Emerich DW, Burris RH. 1976. Proc. Natl. Acad. Sci. USA 73:4369-73

32. Emerich DW, Hageman RV, Burris RH. 1981. Adv. Enzymol. 52:1-22

33. Hausinger RP, Howard JB. 1983. J. Biol. Chem. 258:13486-92

34. Howard JB, Davis R, Moldenhauer B, Cash VL, Dean D. 1989. J. Biol. Chem. 264:11270-74

35. Schulz GE. 1992. Curr. Opin. Struct. Biol. 2:61-67

36. Schulz GE, Elzinga M, Marx F, Schirmer RH. 1974. Nature 250:120-23

36a. Kraulis PJ. 1991. J. Appl. Crystallogr. 24:946-50

37. Yates MG. 1992. See Ref. 8, pp. 685-735

38. Walker JE, Saraste M, Runswick MJ, Gay NJ. 1982. EMBO J. 8:945-81

39. Seefeldt LC, Morgan TV, Dean DR, Mortenson LE. 1992. J. Biol. Chem. 267:6680-88

40. Seefeldt LC, Mortenson LE. 1993. Protein Sci. 2:93-102

41. Wolle D, Dean DR, Howard JB. 1992. Science 258:992-95

42. Chang $\mathrm{CL}$, Davis LC, Rider $M$, Takemoto DJ. 1988. J. Bacteriol. 170: 4015-22

43. Adman ET, Watenpaugh $\mathrm{KD}$, Jensen LH. 1975. Proc. Natl. Acad. Sci. USA 72:4854-58

44. Morgan TV, McCracken J, Orme-Johnson WH, Mims WB, Mortenson L, Pcisach J. 1990. Biochemistry 29:307782

45. Zumft W, Mortenson L, Palmer G. 1973. Biochim. Biophys. Acta 292:41321

46. Watt GD, Wang Z-C, Knotts RR. 1986. Biochemistry 25:8156-62

47. Walker GA, Mortenson LE. 1974. Biochemistry 13:2382-88

48. Ljones T, Burris RH. 1978. Biochemistry 17:1866-72

49. Deits TL, Howard JB. 1989. J. Biol. Chem. 264:6619-28

50. Anderson GL, Howard JB. 1984. Biochemistry 23:2118-22

51. Surerus KK, Hendrich MP, Christie PD, Rottgardt D, Orme-Johnson WH, Munck E. 1992. J. Am. Chem. Soc. 114:8579-90

52. Deisenhofer J, Epp O, Miki K, Huber R, Michel H. 1985. Nature 318:618-24

53. Allen JP, Feher G, Yeates TO, Komiya
H, Rees DC. 1987. Proc. Natl. Acad. Sci. USA 84:5730-34

54. Jacobson MR, Cantwell JS, Dean DR. 1990. J. Biol. Chem. 265:19429 33

55. Joerger RD, Loveless TM, Pau RN, Mitchenall LA, Simon BH, Bishop PE. 1990. J. Bacteriol. 172:3400-8

56. Robson RL, Woodley PR, Pau RN, Eady RR. 1989. EMBO J. 8:1217-24

57. Dean DR, Jacobson MR. 1992. See Ref. 8, pp. 763-834

58. Shah VK, Brill W. 1977. Proc. Natl. Acad. Sci. USA 74:3249-53

59. Rawlings J, Shah VK, Chisnell RJ, Brill WJ, Zimmermann R, et al. 1978. J. Biol. Chem. 253:1001-4

60. Nelson MJ, Levy MA, Orme-Johnson WH. 1983. Proc. Natl. Acad. Sci. USA 80:147-50

61. Hoover TR, Robertson AD, Cemy RL, Hayes RN, Imperial J, et al. 1987. Nature 329:855-57

62. Hoover TR, Imperial J, Ludden PW, Shah VK. 1988. Biofactors 1:199-205

63. Brigle KE, Weiss MC, Newton WE, Dean DR. 1987. J. Bacteriol. 169: 1547-53

64. Paustian TD, Shah VK, Roberts GP. 1989. Proc. Natl. Acad. Sci. USA 86:6082-86

65. Liang J, Madden M, Shah VK, Burris RH. 1990. Biochemistry 29:8577-81

66. Robinson AC, Dean DR, Burgess BK. 1987. J. Biol. Chem. 262:14327-32

67. Robinson AC, Chu W, Li J-G, Burgess BK. 1989. J. Biol. Chem, 264:1008895

68. Tal S, Chun TW, Gavini N, Burgess BK. 1991. J. Biol. Chem. 266:10654 57

69. Paustian TD, Shah VK, Roberts GP. 1990. Biochemistry 29:3515-22

70. White TC, Harris GS, Orme-Johnson WH. 1992. J. Biol. Chem. 267:2400716

71. Howard JB, Anderson G, Deits T. 1985. In Nitrogen Fixation Research Progress, ed. HJ Evans, PJ Bottomley, WE Newton, pp. 559-66. Dordrecht: Martinus Nijhoff

72. Zheng L, White RH, Cash VL, Jack RF, Dean DR. 1993. Proc. Natl. Acad. Sci. USA 90:2754-58

73. Howard KS, McLean PA, Hansen FB, Lemley PV, Koblan KS, Orme-Johnson WH. 1986. J. Biol. Chem. 261:772-78

74. Paul W, Merrick M. 1989. Eur. J. Biochem. 178:675-82

75. Eady RR. 1991. Adv. Inorg. Chem. 36:77-102

76. Bishop PE, Premakuman R. 1992. See Ref. 8, pp. 736-62 


\section{HOWARD \& REES}

77. Hageman RV, Burris RH. 1978. Biochemistry 17:4117-24

78. Hageman RV, Orme-Johnson WH, Burris RH. 1980. Biochemistry 19: 2333-42

79. Hageman RV, Burris RH. 1978. Proc. Natl. Acad. Sci. USA 75:2699-702

80. Thorneley RNF, Lowe DJ. 1985. In Molybdenum Enzymes, ed. TG Spiro, pp. 221-84. New York: Wiley

81. Deits TL, Howard JB. 1990. J. Biol. Chem. 265:3859-67

82. Thorneley RNF. 1992. Philos. Trans. $R$. Soc. London Ser. B 336:73-82

83. Wolle D, Kim C, Dean D, Howard JB. 1992. J. Biol. Chem. 267:3667-73

84. Gavini N, Burgess BK. 1992. J. Biol. Chem. 267:21179-86

85. Lowery RG, Chang CL, Davis LC, McKenna M-C, Stevens PJ, Ludden PW. 1989. Biochemistry 28:1206-12

86. Howard JB. 1993. See Ref. 29, pp. 271-89

87. Fisher K, Lowe D, Thorneley R. 1991. Biochem. J. 279:81-85

88. Burns A, Watt GD, Wang ZC. 1985. Biochemistry 24:3932-36

89. Willing AH, Georgiadis MM, Rees DC, Howard JB. 1989. J. Biol. Chem. 264:8499-503
90. Willing A, Howard JB. 1990. J. Biol. Chem. 265:6596-99

91. Thorneley RNF, Ashby GA, Fisher K, Lowe DJ. 1993. See Ref. 29, pp. 290-302

92. Wuttke DS, Bjerrum MJ, Winkler JR, Gray HB. 1992. Science 256:1007-9

93. Farid RS, Moser CC, Dutton PL. 1993. Curr. Opin. Struct. Biol. 3:225-33

94. Hageman RV, Burris RH. 1980. Biochim. Biophys. Acta 591:63-75

95. Wherland S, Burgess BK, Stiefel EI, Newton WE. 1981. Biochemistry 20: $5132-40$

96. Orme-Johnson WH. 1992. Science 257: $1639-40$

97. Deng H, Hoffmann R. 1993. Angew. Chem. Int. Ed. 32:1062-65

98. Scott DJ, Dean DR, Newton WE. 1992. J. Biol. Chem. 267:20002-10

99. Newton WE, Dean DR. 1993. See Ref. 29 , pp. $216-30$

100. Imperial J, Hoover TR, Madden MS, Ludden PW, Shah VK. 1989. Biochemistry 28:7796-99

101. Madden MS, Kindon ND, Ludden PW, Shah VK. 1990. Proc. Natl. Acad. Sci. USA 87:6517-21

102. Koonin EV. 1993. J. Mol. Biol. 229: $1165-74$ 
$\bar{A}$ Annual Review of Biochemistry

Volume 63 (1994)

\section{CONTENTS}

Tryptophan, Oxygen, and Sleep, Osamu Hayaishi

Steroid $5 \alpha$-Reductase: Two Genes/Two Enzymes, David $W$. Russell and Jean D. Wilson

A Molecular Description of Synaptic Vesicle Membrane

TrafFicking, Mark K. Bennett and Richard H. Scheller

Structure and Function of G Protein-Coupled Receptors, Catherine D. Strader, Tung Ming Fong, Michael R. Tota, Dennis Underwood, and Richard A. F. Dixon

The Retroviral Enzymes, Richard A. Katz and Anna Marie Skalka

Nitric Oxide: A physiologic Messenger Molecule, D.S. Bredt and $S . H$. Snyder

Structure, Function, Regulation, and Assembly of D-Ribulose-1,5-BisPhosphate CarboXylase/OXYgenase, Fred C. Hartman and Mark R. Harpel

Nitrogenase: A Nucleotide-Dependent Molecular Switch, James B. Howard and Douglas C. Rees

Role of Chromatin Structure in the Regulation of Transcription by RNA Polymerase II, Suman M. Paranjape, Rohinton T. Kamakaka, and James T. Kadonaga

Quinoenzymes IN BIOLOGY, Judith P. Klinman and David Mu

Intermediate Filaments: Structure, Dynamics, Function, AND Disease, Elaine Fuchs and Klaus Weber

5-Lipoxygenase, A. W. Ford-Hutchinson, M. Gresser, and R. N Young

The Expression of Asymmetry During Caulobacter Cell Differentiation, Yves V. Brun, Greg Marczynski, and Lucille Shapiro 


\section{vi CONTENTS (Continued)}

Molecular Mechanisms of Action of Steroid/Thyroid Receptor Superfamily Members, Ming-Jer Tsai and Bert W. O'Malley

Homeodomain Proteins, Walter J. Gehring, Markus Affolter, and Thomas Bürglin

Escherichia coli Single-Stranded DNA-Binding Protein: Multiple DNA-Binding Modes and CoOperativities, Timothy M. Lohman and Marilyn E. Ferrari

The Biochemistry of Synaptic Regulation in the Central Nervous System, Mary B. Kennedy

Structures and Functions of Multiligand Lipoprotein Receptors: Macrophage Scavenger Receptors and LDL ReCEPTOR-Related Protein (LRP), Monty Krieger and Joachim Herz

The Centrosome and Cellular Organization, Douglas $R$. Kellogg, Michelle Moritz, and Bruce M. Alberts

Energy Transduction by Cytochrome Complexes in MitoCHONDRIAL AND BaCterial Respiration: The EnZymology of Coupling Electron Transfer Reactions to Transmembrane Proton Translocation, Bernard L. Trumpower and Robert B. Gennis

Control of RNA IntTiation and Elongation at tHe HIV-1 Promoter, Katherine A. Jones and B. Matija Peterlin

Regulation of Eukaryotic DNA Replication, Dawn Coverley and Ronald A. Laskey

Function and Structure Relationships in DNA Polymerases, Catherine M. Joyce and Thomas A. Steitz

Calcium Channel Diversity and Neurotransmitter Release: The $\omega$-Conotoxins AND $\omega$-Agatoxins, Baldomero $M$. Olivera, George Miljanich, J. Ramachandran, and Michael E. Adams

Genetic and Biochemical Studies of Protein N-Myristoylation, D. Russell Johnson, Rajiv S. Bhatnagar, Laura J. Knoll, and Jeffrey I. Gordon

Repair of Oxidative Damage to DNA: Enzymology and Biology, Bruce Demple and Lynn Harrison 
GTPases: Multifunctional Molecular Switches Regulating

Vesicular Traffic, Claude Nuoffer and William E. Balch

Homologous Pairing and DNA Strand-Exchange Proteins, Stephen C. Kowalczykowski and Angela K. Eggleston

Signal Transmission between the Plasma Membrane and

Nucleus of T LyMPHOCYTES, Gerald $R$. Crabtree and Neil A.

Clipstone

INDEXES

$\begin{array}{ll}\text { Author Index } & 1085\end{array}$

Subject Index 1149

Cumulative Index of Contributing Authors, Volumes 59-63 1189

Cumulative Index of Chapter Titles, Volumes 59-63 